\title{
Analysis of Information Technology Governance in Bina Darma Foundation of Salatiga Using COBIT 5 Framework
}

\author{
Dwi Puspitasari ${ }^{1}$, Hanna Prillysca Chernovita ${ }^{2}$ \\ 1,2Information System Departement, Satya Wacana Christian University, Salatiga, Indonesia \\ Email:1682017108@student.uksw.edu ,2hanna.chernovita@uksw.edu
}

\begin{abstract}
Bina Darma foundation is a non-profit organization established by SWCU and GMKI. The main activities of Bina Darma foundation are leadership training program, journal publishing, and guesthouse rental. However, in daily activities, there are still problems that indicate that IT governance is not running optimally, so an analysis is needed to evaluate it. This study aims to analyze the conditions of IT governance governance in Bina Darma Foundation uses the framework COBIT 5 domain DSS (Delivery, Service, and Support). The result of this research is capability level is currently at level 1 (Performed process), while capability level is expected to be at level 2 (Managed proces). Therefore, recommendations are given so that the IT governance in Bina Darma Foundation can work optimally to support the achievement of the organization's business objectives efficiently.
\end{abstract}

Keywords: IT Governance, COBIT 5, DSS Domain

\section{PENDAHULUAN}

Keberadaan Teknologi Informasi (TI) banyak memberikan pengaruh di berbagai bidang termasuk bagi Sistem Informasi (SI). Sebagian besar perusahaan maupun organisasi saat ini menggunakan SI dan menganggap penerapan TI/SI sebagai bagian penting dalam proses bisnis dan pendukung operasional perusahaan maupun organisasi [1]. Namun, penerapan TI/SI dibutuhkan investasi yang besar dan resiko yang tinggi. Oleh karena itu diperlukan mekanisme tata kelola yang dapat melakukan pengawasan, pemantauan, dan evaluasi secara menyeluruh agar setiap tujuan bisnis organisasi dapat dicapai dengan penggunaan TI [2]. Yayasan Bina Darma Kota Salatiga adalah organisasi non profit yang memiliki tujuan dalam pengembangan kepemimpinan generasi muda di Indonesia. Kegiatan utama dari yayasan ini adalah program pelatihan kepemimpinan, penerbitan jurnal, dan penyewaan wisma. Dalam penyelenggaraan tugas dan 
fungsi Yayasan Bina Darma juga bergantung dengan teknologi informasi seperti pendataan alumni, pengelolaan aset, laporan keuangan, dan publikasi jurnal.

Namun, ditemukan beberapa permasalahan yang berkaitan dengan pengelolaan TI seperti pengelolaan Sumber Daya Manusia (SDM) yang berkaitan dengan TI belum sesuai, koneksi internet yang belum stabil, dan belum adanya pencadangan data sehingga sering terjadinya risiko kehilangan data. Maka dari itu perlunya audit dan analisis untuk memberikan evaluasi terhadap kondisi tata kelola Teknologi Informasi di Yayasan Bina Darma saat ini, dan juga dapat memberikan strategi yang berguna untuk perbaikan di masa yang akan datang [3].

Evaluasi kinerja teknologi informasi dapat dilakukan dengan menggunakan Control Objectives for Information and related Technology (COBIT) 5. COBIT 5 menyediakan kerangka kerja dan panduan yang rinci bagi manajemen, pemilik proses bisnis, pemakai dan auditor dengan memperhatikan segala aspek tata kelola teknologi informasi mulai dari sisi people, skills, competencies, services, infrastructure, dan applications [4]. Domain Delivery, Service, and Support (DSS) berkaitan dengan pengiriman/ penyampaian yang aktual dan dukungan layanan yang dibutuhkan, meliputi pelayanan, pengelolaan keamanan dan kontinuitas, dukungan layanan bagi pengguna serta manajemen data fasilitas operasional [5].

Penelitian ini dilakukan untuk menganalisis kondisi tata kelola TI di Yayasan Bina Darma menggunakan framewok COBIT 5 domain DSS. COBIT 5 dipilih karena merupakan sebuah model framework tata kelola yang representatif dan menyeluruh terhadap seluruh proses TI [6].

Pada penelitian yang dilakukan oleh Achyar Al-Rasyid mengenai analisis audit sistem informasi berbasis COBIT 5 pada domain Deliver, Service, and Support (DSS) studi kasus SIM-BL di unit CDC PT Telkom Pusat.Tbk. Dari hasil penilaian didapatkan bahwa untuk DSS01, DSS03, DSS04, DSS05 dan DSS06 berada pada level 4, yaitu Predictable Process, dan Level target yang ingin dicapai adalah 5 yaitu Optimizing process [7]. Penelitian selanjutnya yaitu oleh Andreas Wiraniagara dan Agustinus Fritz Wijaya tentang analisis tata kelola teknologi informasi menggunakan framework. COBIT 5 domain Deliver, Service, and Support (DSS) studi kasus Yayasan Eka Tjipta. Hasil dari penelitian ini adalah rekomendasi dari permasalahan penggunaan tata kelola teknologi informasi di Yayasan Eka Tjipta [2].

\section{METODOLOGI PENELITIAN}

Dalam melakukan penelitian di Yayasan Bina Darma, menggunakan metode penelitian yaitu pendekatan deskriptif kualitatif, metode ini mencakup pengumpulan data, mengelola data, dan menganalisis data supaya mendapatkan gambaran tentang kondisi tata kelola TI dengan standar COBIT 5. Data yang 
Vol. 1, No. 1, March 2019

p-ISSN: 2656-5935 http://journal-isi.org/index.php/isi e-ISSN: 2656-4882

diperoleh berupa data primer yang nantinya diolah dari hasil penelitian dan observasi.

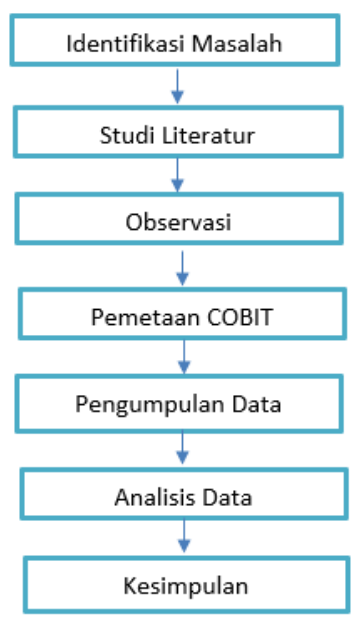

Gambar 1. Tahapan Penelitian

Tahap pertama yang dilakukan adalah studi literatur yaitu penulis menyatukan informasi dan mempersiapkan pedoman dalam penelitian yaitu COBIT 5. Tahap berikutnya adalah melakukan observasi tentang tempat studi kasus.

Tahapan berikutnya adalah pemetaan COBIT 5 yaitu menyelaraskan tujuan bisnis organisasi dengan tujuan bisnis TI di Yayasan Bina Darma. Dilakukan pemetaan Governance Objective (GO) dengan Enterprise Goals (EG). Setelah Enterprise Goals (EG) terpilih dipetakan dengan IT Related Goals (ITRG)[8] . IT Related Goals (ITRG) yang terpilih dipetakan dengan IT Process (ITP) berdasarkan pada COBIT 5 : Enabling Process [9] [10].

Tahap berikutnya yaitu melakukan pengumpulan data melalui observasi dan wawancara dengan narasumber yang telah ditetapkan melalui RACI chart. RACI Chart merupakan matriks dari semua aktivitas dan wewenang pada organisasi yang membantu dalam mengambil keputusan [11]. Observasi dilakukan selama 3 bulan dengan mengamati dan menggunakan TI yang ada di Yayasan Bina Darma. Dilakukan juga wawancara untuk mendapatkan keterangan secara lisan oleh responden dengan pertanyaan singkat yang sesuai dengan domain-domain yang menjadi fokus dalam penelitian ini. Wawancara dilakukan dengan staf TI dan penggurus yayasan yang diwakilkan staf administrasi secara langsung dan dilakukan dokumentasi dengan rekaman wawancara.

Setelah terkumpulnya data, tahapan selanjutnya adalah melakukan analisis data. Analisis dilakukan menggunakan hasil wawancara dan observasi menurut domain-domain dari framework COBIT 5. Setelah dilakukan analisa, akan 
diberikan rekomendasi untuk memperbaiki kondisi tata kelola teknologi yang saat ini dirasa belum optimal. Tahapan yang terakhir adalah menyusun kesimpulan, dari hasil analisis akan menghasilkan nilai dari Capability level di Yayasan Bina Darma yang akan menghasilkan kesimpulan. Kesimpulan dapat menjadi acuan dalam membuat rekomendasi dan saran perbaikan kepada yayasan.

\section{PEMBAHASAN}

Narasumber dalam penelitian ini dibagi ke dalam 4 bagian pada RACI (Responsibility, Accountable, Consulted, dan Informed) yang ditujukkan pada Tabel 1.

Tabel 1. Pemetaan RACI Chart [12]

\begin{tabular}{clc}
\hline RACI & \multicolumn{1}{c}{ Fungsi dan Peran } & Jabatan \\
\hline Responsible & $\begin{array}{l}\text { Bertanggungjawab melaksanakan } \\
\text { dan menyelesaikan aktivitas yang } \\
\text { menjadi tanggung jawabnya. }\end{array}$ & Staf TI \\
Accountable & $\begin{array}{l}\text { Mengarahkan jalannya } \\
\text { pelaksanaan aktivitas. } \\
\text { Tempat konsultasi pelaksanaan } \\
\text { aktivitas. }\end{array}$ & Staf TI \\
Informed & $\begin{array}{l}\text { Menerima informasi mengenai } \\
\text { pelaksanaan aktivitas. }\end{array}$ & Penggurus Yayasan \\
\hline
\end{tabular}

Visi Yayasan Bina Darma adalah menjadi pusat pembinaan dan pengembangan pemimpin visioner yang berwawasan kebangsaan dan berwawasan oikumenis.

Misi Yayasan Bina Darma adalah bersama dengan berbagai pihak membina dan mengembangkan pemimpin yang memiliki komitmen moral, kepedulian sosial, keterampilan transformatif, dan keterampilan manajerial.

Tahap pertama adalah melakukan analisis tujuan strategis di Yayasan Bina Darma. Analisis menggunakan Balanced scorecard (BSC) dengan 4 perspektif yaitu finansial, pelanggan, internal, dan pembelajaran dan pengembangan.

Tabel 2. Hasil Analisis Tujuan Strategis Yayasan

\begin{tabular}{ccl}
\hline Perspektif & \multicolumn{1}{c}{ Tujuan Strategis } \\
\hline Finansial & Mengelola pemakaian dana untuk \\
& & keberlangsungan bisnis yayasan \\
Pelanggan & Mempersiapkan generasi muda Kristen \\
& yang kreatif, mampu mengembangkan diri \\
& secara terus menerus, dan berperilaku etis. \\
& $\bullet$ & Meningkatkan aplikasi TI untuk \\
Internal & menunjang proses bisnis organisasi. \\
&
\end{tabular}


Vol. 1, No. 1, March 2019

p-ISSN: 2656-5935 http://journal-isi.org/index.php/isi e-ISSN: 2656-4882

Perspektif Tujuan Strategis

Pembelajaran dan

- Merancang program pelatihan untuk pengembangan pegawai untuk meningkatkan kemampuan dan kompetensi SDM melalui pelatihan workshop.

Tahap berikutnya adalah melakukan analisis dan penyelarasan tujuan strategis Yayasan Bina Darma dengan Enterprise Goals dalam COBIT 5. Didalam proses analisisnya akan dilihat keterkaitan antara tujuan strategis Yayasan Bina Darma dengan Enterprise Goals COBIT 5. Tabel 3 merupakan Enterprise Goals yang terkait dengan Enterprise Goals COBIT 5.

Tabel 3. Enterprise Goals Terpilih

\begin{tabular}{ccll}
\hline No & $\begin{array}{c}\text { Kode } \\
\text { Enterprise } \\
\text { Goals } \\
\text { COBIT 5 }\end{array}$ & \multicolumn{1}{c}{ Deskripsi } & \multicolumn{1}{c}{$\begin{array}{c}\text { Keterkaitan } \\
\text { Enterprise } \\
\text { Goals }\end{array}$} \\
& & Stakeholder value of business invesment & \multicolumn{1}{c}{$\begin{array}{c}\text { Yasan Bina } \\
\text { Darma }\end{array}$} \\
\hline 1 & EG1 & Tidak terkait \\
2 & EG2 & Portofolio of competitive products and services & Tidak terkait \\
3 & EG3 & Managed business risks (Safeguarding assets) & Tidak terkait \\
4 & EG4 & Compliance with external laws and regulations & Tidak terkait \\
5 & EG5 & Financial Transparency & Ada keterkaitan \\
6 & EG6 & Customer oriented service culture & Ada keterkaitan \\
7 & EG7 & Business service continuity and availability & Tidak terkait \\
8 & EG8 & Agile responses to a changing business environment & Tidak terkait \\
9 & EG9 & Information based strategic decision making & Ada keterkaitan \\
10 & EG10 & Optimisation of service delivery costs & Tidak terkait \\
11 & EG11 & Optimisation of business process functionality & Tidak terkait \\
12 & EG12 & Optimisation of business process costs & Tidak terkait \\
13 & EG13 & Managed business change programmes & Tidak terkait \\
14 & EG14 & Operational and staff productivity & Ada keterkaitan \\
15 & EG15 & Compliance with internal policies & Ada keterkaitan \\
16 & EG16 & Skilled and motivated people & Tidak terkait \\
17 & EG16 & Product and business innovation culture & Tidak terkait \\
\hline & & &
\end{tabular}

Selanjutnya dilakukan pemetaan Enterprise Goals COBIT 5 yang sudah terpilih dengan IT-related goals (ITRG).Tabel 4 menunjukkan Enterprise Goals dan IT-related goals yang terpilih : 
Vol. 3, No. 1, March 2021

p-ISSN: 2656-5935 http://journal-isi.org/index.php/isi e-ISSN: 2656-4882

Tabel 4. Enterprise Goals dan IT-related goals

\begin{tabular}{cccc}
\hline No & $\begin{array}{c}\text { Kode Enterprise } \\
\text { Goals COBIT 5 }\end{array}$ & $\begin{array}{c}\text { Keterkaitan Enterprise Goals } \\
\text { Yayasan Bina Darma }\end{array}$ & $\begin{array}{c}\text { IT-related goals } \\
\text { COBIT 5 }\end{array}$ \\
\hline 1 & EG5 & Ada keterkaitan & 6 \\
2 & EG6 & Ada keterkaitan & 1,7 \\
3 & EG9 & Ada keterkaitan & 1,14 \\
4 & EG14 & Ada keterkaitan & 8,16 \\
5 & EG16 & Ada keterkaitan & 16 \\
\hline
\end{tabular}

Selanjutnya dilakukan pemetaan ITRG yang terpilih dengan IT Process. Hal ini dilakukan untuk memperoleh proses-proses TI pada COBIT khususnya domain DSS yang yang memiliki hubungan dengan tujuan bisnis serta tujuan IT organisasi. Tabel 5 menunjukkan hasil pemetaan ITRG terpilih dengan IT Process:

Tabel 5. IT-related goals dan IT Process

\begin{tabular}{|c|c|c|}
\hline No & $\begin{array}{l}\text { IT-related } \\
\text { goals }\end{array}$ & IT Process \\
\hline 1 & IT-G1 & $\begin{array}{l}\text { EDM01, EDM02, APO01, APO02, APO03, APO05, } \\
\text { APO07, APO08, BAI01, BAI02 }\end{array}$ \\
\hline 2 & IT-G6 & $\begin{array}{l}\text { EDM02, EDM03, EDM05, APO06, APO12, APO13, } \\
\text { BAI09 }\end{array}$ \\
\hline 3 & IT-G7 & $\begin{array}{l}\text { EDM01, EDM02, EDM05, APO02, APO08, APO09, } \\
\text { APO10, APO11, BAI02, BAI03, BAI04, BAI06, DSS01, } \\
\text { DSS02, DSS03, DSS04, DSS06, MEA01 }\end{array}$ \\
\hline 4 & IT-G8 & APO04, BAI05, BAI07 \\
\hline 5 & IT-G14 & APO09,APO13,BAI04,BAI10,DSS03,DSS04 \\
\hline 6 & IT-G16 & EDM04, APO01, APO07 \\
\hline
\end{tabular}

Berbagai temuan yang dihasilkan melalui pengambilan data wawancara dan observasi terlihat di tabel 6 :

Tabel 6. Hasil Temuan Sub Domain DSS

\begin{tabular}{ccc}
\hline Proses Domain & \multicolumn{2}{c}{ Hasil Temuan } \\
\hline DSS01 - Mengelola operasi & - Dalam mengoperasikan TI belum \\
& dilakukan secara optimal karena belum \\
& memiliki SOP dalam perawatan \\
& komputer dan sistem. \\
& - Fasilitas internet sering down. \\
& - Belum mempunyai jadwal monitoring \\
& berkala kepada sistem. \\
& Tidak mempunyai jadwal pelatihan
\end{tabular}




p-ISSN: 2656-5935 http://journal-isi.org/index.php/isi e-ISSN: 2656-4882

DSS03 - Mengelola masalah

DSS04 - Mengelola

keberlanjutan

DSS05 - Mengelola keamanan layanan

DSS06 - Mengelola kontrol proses bisnis khusus bagian TI untuk karyawan.

- Belum ada prosedur mengenai insiden keamanan, tetapi sudah ada upaya untuk mengidentifikasi penyebab masalah.

- Belum melakukan pencatatan masalah TI.

- Tidak ada dokumentasi untuk permasalahan yang ada.

- Dalam mengatasi permasalahan sudah dibagi tugasnya kepada staf terkait.

- Belum memiliki SOP untuk perawatan sistem dan database.

- SOP Teknologi Informasi pada yayasan masih kurang dan belum berjalan secara optimal.

- Di dalam komputer sudah memiliki antivirus dan firewall.

- Belum melakukan kegiatan pencegahan tentang ancaman-ancaman yang potensial.

- Penyelarasan untuk mengontrol proses bisnis dengan tujuan di yayasan sudah berjalan dengan baik.

- SOP untuk mengontrol proses bisnis masih terbatas dan perlu diperbarui.

Nilai capability level COBIT 5 didapatkan dari hasil wawancara dengan responden

RACI Chart. Tabel 7 adalah hasil penilaian dari temuan yang didapat :

Tabel 7. Hasil Pengukuran Tingkat kematangan

\begin{tabular}{llcccccc}
\hline $\begin{array}{l}\text { Process } \\
\text { ID }\end{array}$ & $\begin{array}{l}\text { Process } \\
\text { Name }\end{array}$ & Level 0 & Level 1 & Level 2 & Level 3 & Level 4 & Level 5 \\
\hline DSS01 & $\begin{array}{l}\text { Manage } \\
\text { Operations }\end{array}$ & & 1 & & & & \\
& Manger & & & & &
\end{tabular}

DSSO2 Manage 


\begin{tabular}{lll}
\hline p-ISSN: 2656-5935 & http://journal-isi.org/index.php/isi & e-ISSN: 2656-4882 \\
\hline & $\begin{array}{l}\text { Service } \\
\text { Requests and } \\
\text { Incidents } \\
\text { DSS03 }\end{array}$ & 1 \\
Manage & $\begin{array}{l}\text { Problems } \\
\text { Manage }\end{array}$ \\
DSS05 & $\begin{array}{l}\text { Continuity } \\
\text { Manage } \\
\text { Security } \\
\text { Services } \\
\text { Manage } \\
\text { Business } \\
\text { Process } \\
\text { Controls }\end{array}$ & 1 \\
\hline
\end{tabular}

Berikut bahasan kondisi lebih rinci mengenai sub domain DSS yang ada :

1. DSS01 (Manage Operations), Hasil capability level berada pada level 1 yaitu performed process yang artinya proses sudah diimplementasikan dan mencapai tujuan tetapi belum ada manajemen yang mengontrol. Pada proses ini dalam mengoperasikan TI belum dilakukan secara optimal karena belum memiliki SOP dalam perawatan komputer dan sistem.

2. DSSO2 (Manage Service Requests and Incidents), Hasil capability level berada pada level 1 yaitu performed process yang artinya Yayasan Bina Darma sudah menjalankan tujuan penanganan pengelolaan permintaan layanan dan insiden yang terjadi belum ada prosedur terkait.

3. DSS03 (Manage Problems), Hasil capability level berada pada level 1 yaitu performed process yang artinya Yayasan Bina Darma sudah melaksanakan tujuan mengenai penanganan masalah tetapi tidak ada dokumen terkait permasalahan yang ada.

4. DSS04 (Manage Continuity), Hasil capability level berada pada level 1 yaitu performed process yang artinya Yayasan Bina Darma sudah melaksanakan tujuan pengelolaan keberlanjutan. SOP Teknologi Informasi pada bagian aktivitas tertentu tidak tersedia.

5. DSS05 (Manage Security Services), Hasil capability level berada pada level 1 yaitu performed process. Dari proses ini komputer yang terdapat di Yayasan Bina Darma sudah memiliki antivirus dan firewall untuk keamanan.

6. DSS06 (Manage Business Process Controls), Hasil capability level berada pada level 1 yaitu performed process. Dimana yayasan sudah melakukan penyelarasan untuk mengontrol proses bisnis dengan tujuan di yayasan.

Analisis kesenjangan dilakukan untuk mencari selisih dari capability level yang didapat dengan level yang ingin dicapai oleh Yayasan Bina Darma. Hal ini dikarenakan 
Vol. 1, No. 1, March 2019

p-ISSN: 2656-5935 http://journal-isi.org/index.php/isi e-ISSN: 2656-4882

Tabel 8. Analisa Kesenjangan

\begin{tabular}{cccc}
\hline Process ID & Level Sekarang & $\begin{array}{c}\text { Level yang } \\
\text { diharapkan }\end{array}$ & $\boldsymbol{G A P}$ \\
\hline DSS01 & 1 & 2 & 1 \\
DSS02 & 1 & 2 & 1 \\
DSS03 & 1 & 2 & 1 \\
DSS04 & 1 & 2 & 1 \\
DSS05 & 1 & 2 & 1 \\
DSS06 & 1 & 2 & 1 \\
\hline
\end{tabular}

Berdasarkan hasil analisis yang sudah dilakukan guna meningkatkan capability level yang didapat sekarang dengan target yang diharapkan pada domain DSS. Berikut rekomendasi yang diberikan untuk meningkatkan kualitas tata kelola TI di Yayasan Bina Darma :

1) Rekomendasi DSS01

a. Membuat SOP yang jelas tentang perawatan komputer dan sistem dan melakukan analisis perangkat TI untuk mencegah ancaman yang akan timbul.

b. Melakukan monitoring secara berkala agar mengetahui bagaimana kondisi operasional TI dan dibuat dokumentasi untuk bahan evaluasi.

c. Perlu melakukan pelatihan TI untuk setiap karyawan dan menambah tenaga kerja TI yang kompeten dibidangnya.

2) Rekomendasi DSS02

a. Menyusun prosedur mengenai jenis-jenis insiden yang sudah dihadapi dan mungkin akan terjadi.

b. Membuat dokumentasi dan klasifikasi terhadap jenis layanan dan insiden yang dilayani.

3) Rekomendasi DSS03

a. Mendokumentasikan dan menganalisa masalah yang ada.

b. Membuat sistem yang dapat memantau jalannya penyelesaian masalah.

4) Rekomendasi DSS04

a. Melakukan evaluasi pada SOP TI agar mengetahui bagian yang masih terdapat kendala

b. Menambahkan SOP yang mengatur pengelolaan TI dari sistem hingga database.

5) Rekomendasi DSS05

a. Melakukan pembaharuan antivirus secara berkala untuk melindungi perangkat dari virus dan malware.

b. Melakukan filter untuk melindungi informasi yang tidak diminta

6) Rekomendasi DSSO6

a. Menetapkan tujuan yang jelas tentang proses bisnis yayasan, lalu mendokumentasikan dan mengevaluasi untuk keberlangsungan yayasan ke depan. 
b. Memonitor kegiatan proses bisnis dengan memperbarui SOP dan mengidentifikasi aktivitas yang berpengaruh pada proses bisnis.

\section{KESIMPULAN}

Berdasarkan hasil penelitian dan analisis yang telah dilakukan di Yayasan Bina Darma Salatiga menggunakan COBIT 5 domain DSS dapat disimpulkan bahwa hasil penelitian capability level domain DSS masih berada di level 1 yaitu performed process yang artinya bahwa Yayasan Bina Darma Salatiga sudah mengimplementasikan dan sudah melakukan sesuai tujuan. Sedangkan level yang diharapkan adalah level 2 yaitu managed process. Oleh sebab itu, GAP yang dihasilkan pada proses DSS dari level sekarang dengan level yang diharapkan adalah 1. Untuk meningkatkan capability level agar mencapai target yang diharapkan terdapat rekomendasi perbaikan kapabilitas yang diharapkan dapat meningkatkan kinerja TI diantaranya dengan membuat SOP yang jelas tentang perawatan komputer dan sistem, monitoring dan mendokumentasikan kondisi operasional TI, melakukan pelatihan TI kepada karyawan dan melakukan evaluasi agar setiap proses TI dapat dilakukan secara maksimal demi kelanjutan proses bisnis yayasan.

\section{DAFTAR PUSTAKA}

[1] A. F. Wijaya and A. T. Andani, "Evaluasi Kinerja Sistem Informasi EFiling Menggunakan Cobit 5 Pada Kantor Pelayanan Pajak Pratama Kota Salatiga," J. Terap. Teknol. Inf., vol. 1, no. 1, pp. 61-70, 2017, doi: 10.21460/jutei.2017.11.9.

[2] A. Wiraniagara and F. Wijaya, "Analisis Tata Kelola Teknologi Informasi Menggunakan Framework Cobit 5 Domain Deliver Support and Service ( Studi Kasus : Yayasan Eka Tjipta , Jakarta )," vol. 5, pp. 663-671.

[3] H. P. Prasojo and Pujiono, "Analisis Tata Kelola Teknologi Informasi Dengan Menggunakan Framework Cobit 5 Domain DSS01 ( Manage Operations ) Pada BPS Provinsi Jawa Tengah," J. JOINS Udinus, vol. 1, no. x, pp. 67-76, 2017.

[4] R. K. Candra, I. Atastina, and Y. Firdaus, "Audit Teknologi Informasi menggunakan Framework COBIT 5 Pada Domain DSS (Delivery, Service, and Support) (Studi Kasus: iGracias Telkom University)," eProceeding Eng., vol. 2, no. 1, pp. 1129-1445, 2015.

[5] U. Cahyani, I. Aknuranda, and A. R. Perdanakusuma, "Evaluasi Layanan BPJSTK Mobile Dengan Menggunakan Domain Deliver, Service and Support Berdasarkan Framework COBIT 5 (Studi Kasus: BPJS Ketenagakerjaan Cabang Mataram)," J. Pengemb. Teknol. Inf. dan Ilmu Komput., vol. 2, no. 8, pp. 2382-2391, 2018, [Online]. Available: http://jptiik.ub.ac.id. 
[6] A. D. Manuputty and E. C. Papilaya, "Analisis Tata Kelola Teknologi Informasi pada Kantor Pelayanan Pajak Pratama Ambon menggunakan Framework COBIT 5 . 0," CITEE Tek. Elektro Teknol. Inf. UGM, pp. 2425, 2019.

[7] A. Al-rasyid, "Analisis Audit Sistem Informasi Berbasis COBIT 5 Pada Domain Deliver, Service, and Support (DSS ) (Studi Kasus : SIM-BL di Unit CDC PT Telkom Pusat. Tbk ) Analysis-Based Information Systems Audit COBIT 5 In the Domain Deliver, Service, and Support," 2015.

[8] ISACA.2012, COBIT 5: A business framework for the governance and management of enterprise IT COBIT 5, vol. 34, no. 1. 2012.

[9] R. A. Fajrin, M. Murahartawaty, and S. F. S. Gumilang, "Perancangan Tata Kelola Teknologi Informasi di BAPAPSI Pemkab Bandung Menggunakan framework COBIT 5 Pada Domain EDM dan DSS," J. Inf. Syst. Eng. Bus. Intell., vol. 2, no. 2, p. 74, 2016, doi: 10.20473/jisebi.2.2.7480.

[10] ISACA, COBIT ® Process Assessment Model (PAM): Using COBIT ® 5. 2013.

[11] S. D. Rehatta and A. D. Manuputty, "Measurement of the Maturity Level of IT Governance in Implementing Personnel Management Information System Using the MEA Domain COBIT 5 Framework In Regional Personnel, Education and Training Agency," J. Inf. Syst. Informatics, vol. 1, no. 2, pp. 123-135, 2019, doi: 10.33557/journalisi.v1i2.16.

[12] ISACA, Enabling Processes. 2012. 